\title{
STATISTICAL INVESTIGATION OF I-SHAPED STIFFENED RECTANGULAR PLATE BY TAGUCHI RESPONSE EVALUATION
}

DOI : 10.36909/jer.ICIPPSD.15509

\author{
Molwane O.B. *, Agarwal A. **, Letsatsi M.T.* \\ *Department of Industrial Design \& Technology, FET, University of Botswana, Gaborone, \\ Botswana. \\ ** Department of Mechanical Engineering, FET, University of Botswana, Gaborone, \\ Botswana \\ * Corresponding Author: letsatsim@ub.ac.bw
}

\begin{abstract}
In this research, the buckling of stiffened rectangular plate with square opening is studied using techniques of FEA. The stiffener used for analysis is I shaped placed on edges and in vertical configuration. Critical buckling loads are determined from load multiplier values obtained from FEA simulation. The features of stiffener are further optimized with Taguchi response technique to acquire essential responses of variables with respect to yield variables. The sensitivities of various optimization parameters are also determined. The results indicated that substantial enhancement in buckling resistance can be achieved through optimized dimensions of stiffeners. For safety-factor least both lower width and upper width shows positive sensitivities with lower width sensitivity rate is 54.041 (positive) and upper width rate is additionally 54.041 (positive). Hence, both upper width measurements and lower width has same impact on factor noticed for SPSW.
\end{abstract}

Key words: Taguchi technique; finite element analysis; buckling; deflection; stiffness.

\section{INTRODUCTION}

The structural stability of plates to a large extent depends upon its buckling resistance and after buckling attributes. Compressive stresses acting on thin-walled sections causes local buckling. These local buckling are due to patch loads (Agarwal, Seretse, Letsatsi, et al., 2020). During buckling as mid plane stretching of plates, the membrane forces are developed due to out-ofplane deflections. Longitudinal strips in vicinity of edge remain straight due to constraint while 
strips away from edge are more prone to buckling which signifies loss of initial stiffness for later case and rectangular plate in uniform compression shown in figure 1.

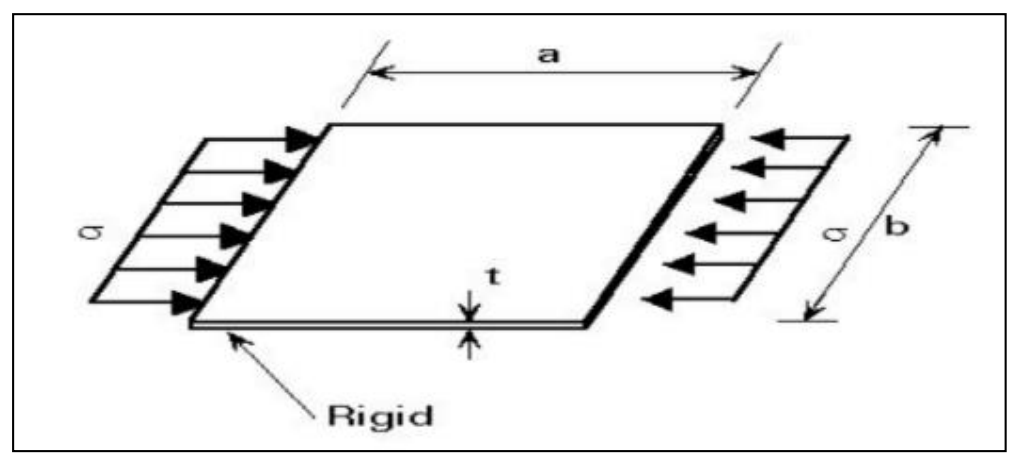

Figure 1 Rectangular plate in uniform compression (Letsatsi, Seretse, and Agarwal 2020) The applications of rectangular plates have begun in steel plate shear walls from last 40 decades. This section reviews the previous works in investigation of steel plate shear walls encompassing rectangular plates as infill panels subjected to multiaxial loadings. Rezai (1999) has investigated buckling behaviours conduct by characterizing orthotropic properties of infill boards coincided utilizing shell components. The orthotropic conduct shows distinctive elasticity in $\mathrm{x}, \mathrm{y}$ and $\mathrm{z}$ bearings, encouraged to demonstrate diverse solidness for pressure inclining when contrasted with tension diagonal. The infill plates are arranged to 450 point to level. Emovon and Mgbemena (2019) has used FMEA technique in addition to Taguchi technique to observe more precise decisions. Grondin; and Alaa E. Elwi (2003) did an express examination that included kinematic hardening material. The outcomes are approved with test results and, accordingly, parametric examinations have been led to distinguish the boundaries that impact the inflexibility and quality of SPSW frameworks. The normalized cutting limit of the board increments for a viewpoint proportion of under one. Takahashi, Y; Takemoto, Y; Takeda, T; Takagi (1973) directed testing on 12 SPSW panels having different stiffener arrangement under inelastic cyclic loading situations. The investigational outcomes have shown higher energy dissipation in stiffened panels as compared to unstiffened panels and stable behaviour of both type of panels. Li et al. (2021)determined the deformation characteristics of slope using simulation-based study which shows the good agreement with the physical field measurements. Timler and Kulak (1983) directed an overview utilizing a multi-strip model in their test utilizing test tests. The test was performed utilizing various examples with along these lines diminished cross-sectional territory. The normal estimations of the filling plate's pressure and the pivotal distortions agree intimately with the exploratory qualities. This was additionally seen with the load deformation curves. Sharma N et al. (2020) conducted research for hardness and tensile strength using Taguchi based design of 
experiments and the conformation process shows the optimal results. (Louca, Pan, and Harding , 1998; Pan and Louca, 1999) have studied stiffened plate by means of 3D FE to ascertain the limited and overall total response of reinforced plate with blast load condition. The results show that structural response is not affected by direction of loading and type of stiffeners used.

\section{METHODOLOGY}

The stiffened designs are more competent in load bearing ability than without stiffeners designs (Vetr and Ghaffari, 2015). The proper structure and suitable place of stiffener is more imperative in enhancing load resistance properties of design otherwise it decreases entire load bearing ability. The starting point of this investigation is to optimize structure of sizes of I shaped stiffeners needed in rectangular plate exerted to vertical loading situations. The material required for shear plates is SS and optimization measurements are beam lower with as well as beam upper width of designs with I shaped stiffeners. The optimization is prepared by Taguchi RS technique as well as structural examination is accompanied by FEM (Letsatsi and Agarwal, 2020). The shear behavior of SPSW is analyzed under vertical loading conditions. The 2D CAD model of SPSW is established with dimensions, ANSYS design modeller and the opening of SPSW is reformed to square shape as shown in fig.2 (a) and fig.2 (b) respectively.

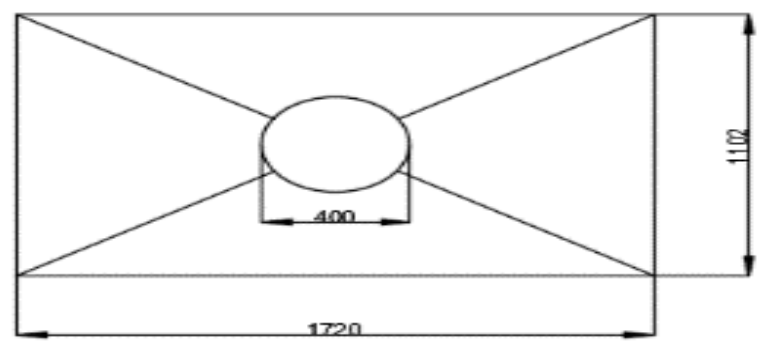

(a)

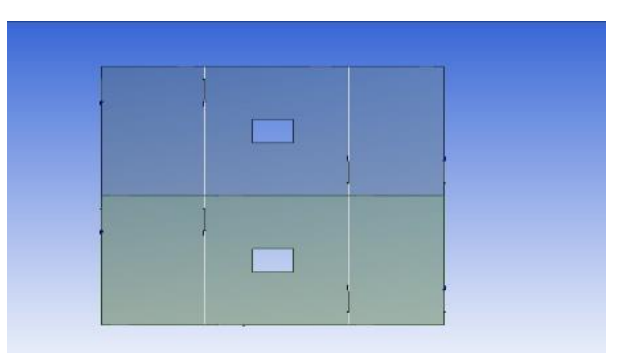

(b)

Figure 2 Schematic of plate with hole (a) and CAD modelling with square opening (b)

The flat plat of SPSW is meshed with brick elements which has better interpolation function and edges are meshed with beam elements. The procedure includes matrix inversions as well as multiplications to find out deformation along with stresses at edges and these outcomes are plotted for overall section edge length (Agarwal, Seretse, Letsatsi, et al. 2020). The number of components produced is 9702 and number of nodes engendered is 10377 . Bottom edge of SPSW is applied with fixed support and upper edge is applied with downward potency of $900 \mathrm{KN}$ as shown in figure 3 (a) and fig.3 (b). The subsequent stage is arrangement 
stage in which programming defines component solidness framework which are amassed to shape global stiffness matrix (Letsatsi et al. 2020).

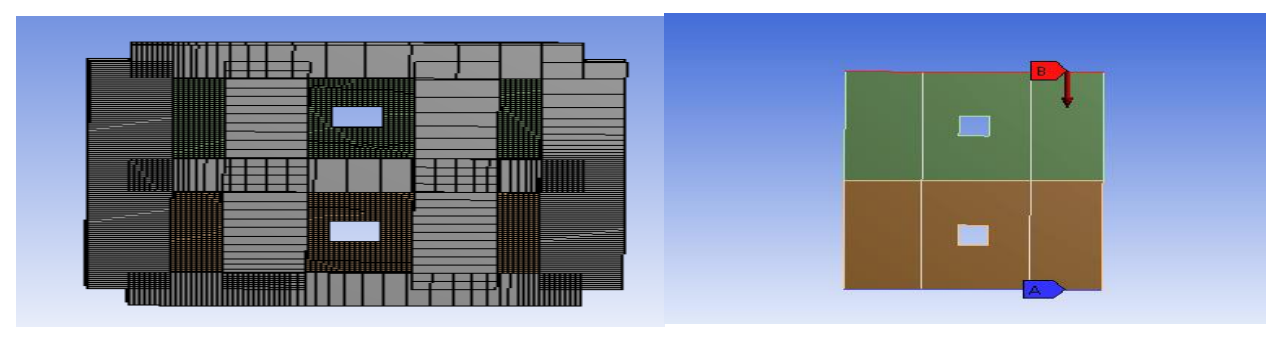

(a)

(b)

Figure 3 rectangular plate Meshed model (a) and Loads \& Boundary (b)

\section{RESULT AND DISCUSSION}

The FE study is required to evaluate stresses, deformation and buckling load which are explained here (Agarwal, Seretse, and Pumwa, 2020). The maximum value of twist is noticed at upper left segment of SPSW with value of $0.425 \mathrm{~mm}$. Move from upper lower to top edge, the value of deformation decreases and other segment of SPSW particularly base bit has immaterial deformation as shown in fig.4 (a). The extreme principal-stress is achieved on shorter Square opening with top value of $165.72 \mathrm{MPa}$ as well as reduces on near places. The upper portion indicates insignificant stresses as presented in fig.4 (b).

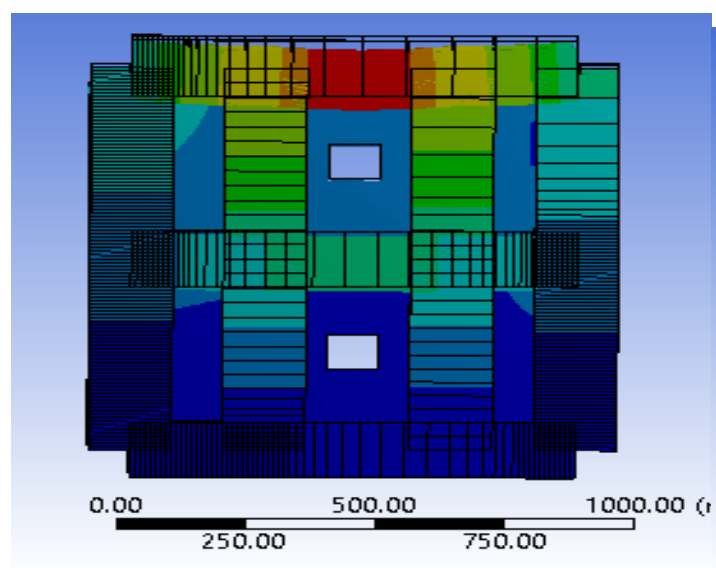

(a)

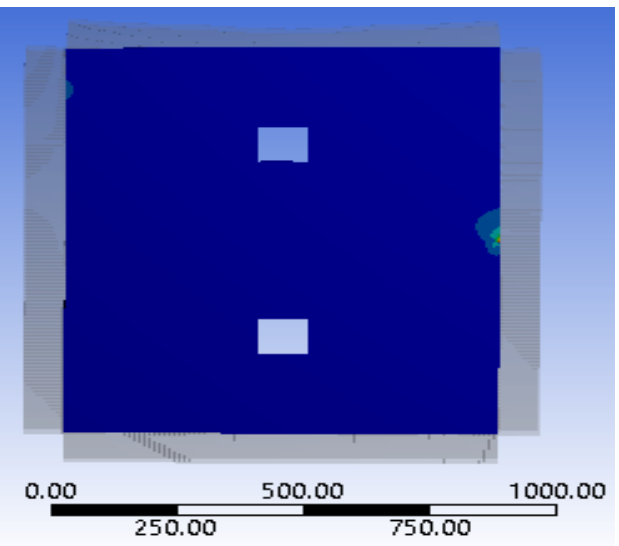

(b)

Figure 4 Square opening with I beams Deformation plot (a) and Max Principal stress (b)

The most extreme strain is found on lower square opening with greatest value of .0008585 and diminishes on close by areas. The upper bit encounters insignificant strain. The greatest strain is gotten on top pillar mid bit with most extreme size of $10438 \mathrm{~N}-\mathrm{m}$ and decreases on close. 
Principal strain and the centre and lower partition encounters immaterial bending movement are shown in fig.5 (a) and fig.5 (b) respectively.

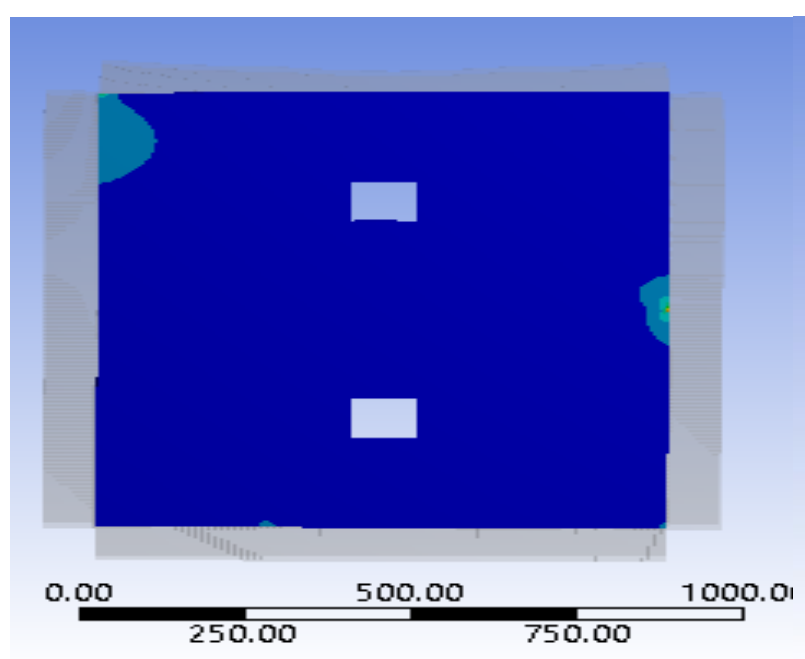

(a)

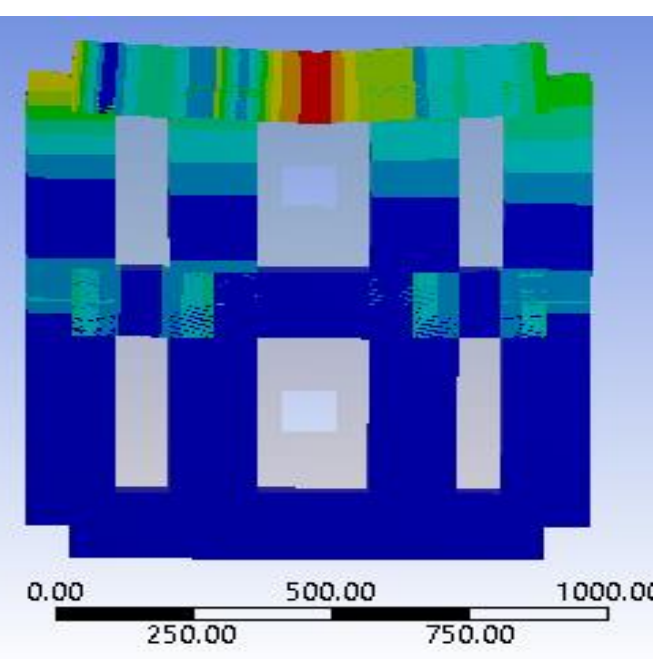

(b)

Figure 5 Square structure with I beams max principal strain (a) and total BM (b)

The smallest secure parameter after analysis is examined to be magnitude of 0.449 . The places of higher secure parameters are stiffeners and top left places and in surrounding of top opening. The complete deformation load capacity multiplier decided from secure parameter is acquired by increasing load multiplier to required one which produces $8652240 \mathrm{~N}$. The reactions which are yield variable are streamlined based on input variable which are autonomous. The autonomous factors are meant by $\mathrm{x}_{1}, \mathrm{x}_{2}, \mathrm{x}_{3} \ldots \ldots \mathrm{x}_{\mathrm{n}}$. These factors are free and constrained by experimenter with unimportant errors. The connection between autonomous variable as well as dependent variable may be communicated like (Agarwal, Seretse, Letsatsi et al., 2020). The reaction of structure which is capacity of numerous structure factors (xi), the reaction surface behaviour may be communicated through considering approx. As a polynomial $y=f(x)$ based on perception information. The 2-V regression model of reaction is produced through following equation (Letsatsi et al., 2020).

$$
y=\beta_{0}+\beta_{1} x_{1}+\beta_{2} x_{2}+\beta_{3} x_{1}^{2}+\beta_{4} x_{2}^{2}+\beta_{5} x_{1} x_{2}
$$

These tests are conducted following the CCD procedure of optimization. The structure points are originated from the DOE is shown in table 1. 
Table 1 Optimization design points.

\begin{tabular}{|c|c|c|c|c|c|c|c|c|}
\hline Name & $\begin{array}{l}\text { P12- } \\
\text { beaml ower } \\
\text { width }\end{array}$ & $\begin{array}{l}\text { P13- } \\
\text { beamlow } \\
\text { erwidth } \\
(\mathrm{mm})\end{array}$ & $\begin{array}{l}\text { P1-Total } \\
\text { Deformation } \\
\text { Load } \\
\text { Multiplier }\end{array}$ & $\begin{array}{l}\text { P5-Overall } \\
\text { BM max (N } \\
\text { mm) }\end{array}$ & $\begin{array}{l}\text { P8-Total } \\
\text { Deformation } \\
\max (\mathrm{mm})\end{array}$ & $\begin{array}{l}\text { P9-Max } \\
\text { PS } \\
\text { (Mpa) }\end{array}$ & $\begin{array}{l}\text { P10-Max } \\
\text { Principal } \\
\text { ES max } \\
\text { mm } \text { mm }^{-1}\end{array}$ & $\begin{array}{l}\text { P11- } \\
\text { Safety } \\
\text { Factor } \\
\text { Min }\end{array}$ \\
\hline $\begin{array}{l}1 \mathrm{DP} \\
0\end{array}$ & 160 & 160 & 9.6136 & $1.0438 \mathrm{E}-+07$ & 0.42563 & 165.72 & $\begin{array}{l}0.000858 \\
28\end{array}$ & $\begin{array}{l}0.4497 \\
4\end{array}$ \\
\hline 2 & 144 & 160 & 9.2713 & $\begin{array}{l}1.0257 \mathrm{E}- \\
+07\end{array}$ & 0.51576 & 173.45 & $\begin{array}{l}0.000883 \\
73\end{array}$ & $\begin{array}{l}0.4184 \\
3\end{array}$ \\
\hline 3 & 176 & 160 & 9.6799 & $\begin{array}{l}1.0661 \mathrm{E}- \\
+\mathrm{O} 7\end{array}$ & 0.44879 & 163.36 & $\begin{array}{l}0.000835 \\
54\end{array}$ & $\begin{array}{l}0 . \% 15 \\
8\end{array}$ \\
\hline 4 & 160 & 144 & 9.2713 & $1.0257 \mathrm{E}-+07$ & 0.51576 & 173.45 & $\begin{array}{l}0.000883 \\
73\end{array}$ & $\begin{array}{l}0.4184 \\
3\end{array}$ \\
\hline 5 & 160 & 176 & 9.6799 & $\begin{array}{l}1.0661 \mathrm{E}- \\
+\mathrm{O} 7\end{array}$ & 0.44879 & 163.36 & $\begin{array}{l}0.000835 \\
54\end{array}$ & $\begin{array}{l}0 . \% 15 \\
8\end{array}$ \\
\hline 6 & 144 & 144 & 9.181 & $\begin{array}{l}1.002 \mathrm{SE}-+\mathrm{O} \\
7\end{array}$ & 0.48271 & 174.73 & $\begin{array}{l}0.000904 \\
42\end{array}$ & $\begin{array}{l}0.4075 \\
1\end{array}$ \\
\hline 7 & 176 & 144 & 9.1637 & $\begin{array}{l}1.0523 \mathrm{E}- \\
+07\end{array}$ & 0.63133 & 169.13 & $\begin{array}{l}0.000855 \\
52\end{array}$ & $\begin{array}{l}0.4423 \\
9\end{array}$ \\
\hline 8 & 144 & 176 & 9.1637 & $\begin{array}{l}1.0523 \mathrm{E}- \\
+07\end{array}$ & 0.63133 & 169.13 & $\begin{array}{l}0.000855 \\
52\end{array}$ & $\begin{array}{l}0.4423 \\
9\end{array}$ \\
\hline 9 & 176 & 176 & 9.9487 & $\begin{array}{l}1.0838 \mathrm{E}- \\
+07\end{array}$ & 0.38062 & 156.67 & $\begin{array}{l}0.000812 \\
27\end{array}$ & $\begin{array}{l}0.4915 \\
8 \\
\end{array}$ \\
\hline
\end{tabular}

The plot is representing the difference data points as well as with line fit shown in fig. 6 (a) $\&(b)$.

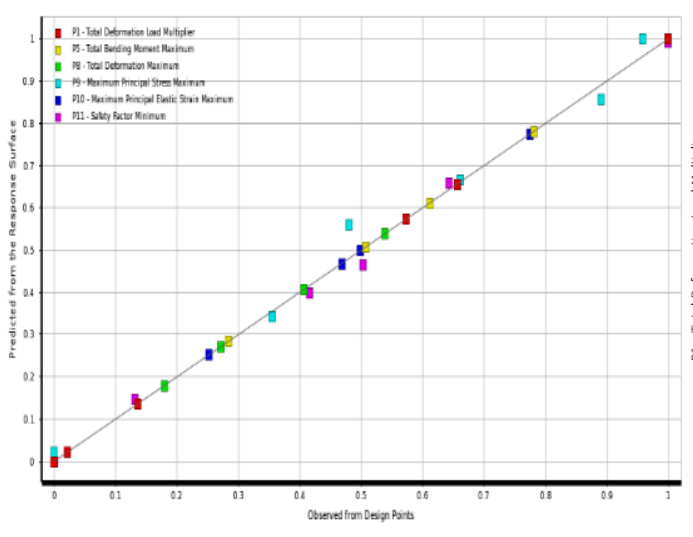

(a)

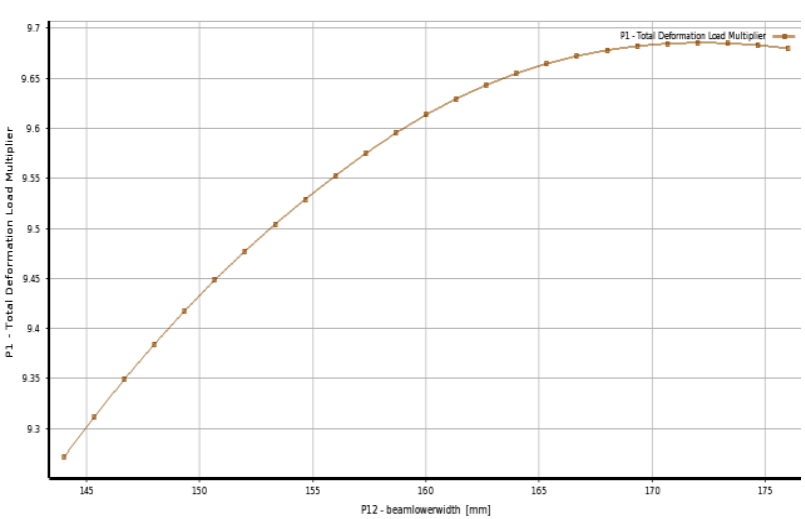

(b)

Figure 6 Beams fit curve (a) and deformationload multiplier vs beam lower width (b)

The integrity of fit bend of direct technique represents the distinction amid of the noticed qualities as well as anticipated estimations of yield amounts. It likewise portrays the exactness of expectation for future arrangement of perceptions. The total deformation vs beam width graph in fig.6 (a) shows linear variation with gradual increase in total deformation load multiplier up-to $175 \mathrm{~mm}$, and minimum at $144 \mathrm{~mm}$ while the total deformation vs upper width 
variation shows linear variation with gradual increase in total deformation up-to $176 \mathrm{~mm}$, and minimum at $144 \mathrm{~mm}$. The least estimation of absolute deformation is gotten for various scopes of pillar upper width as well as bar lower width appeared through dim blue forms. Extreme principal stress is great for beam lower width size of $145 \mathrm{~mm}$, reduces linearly up-to $176 \mathrm{~mm}$ beam lower width. The response surface designing figure 7 shows that, the most extreme complete deformation load multiplier esteem is gotten for width from $170 \mathrm{~mm}$ $175 \mathrm{~mm}$.

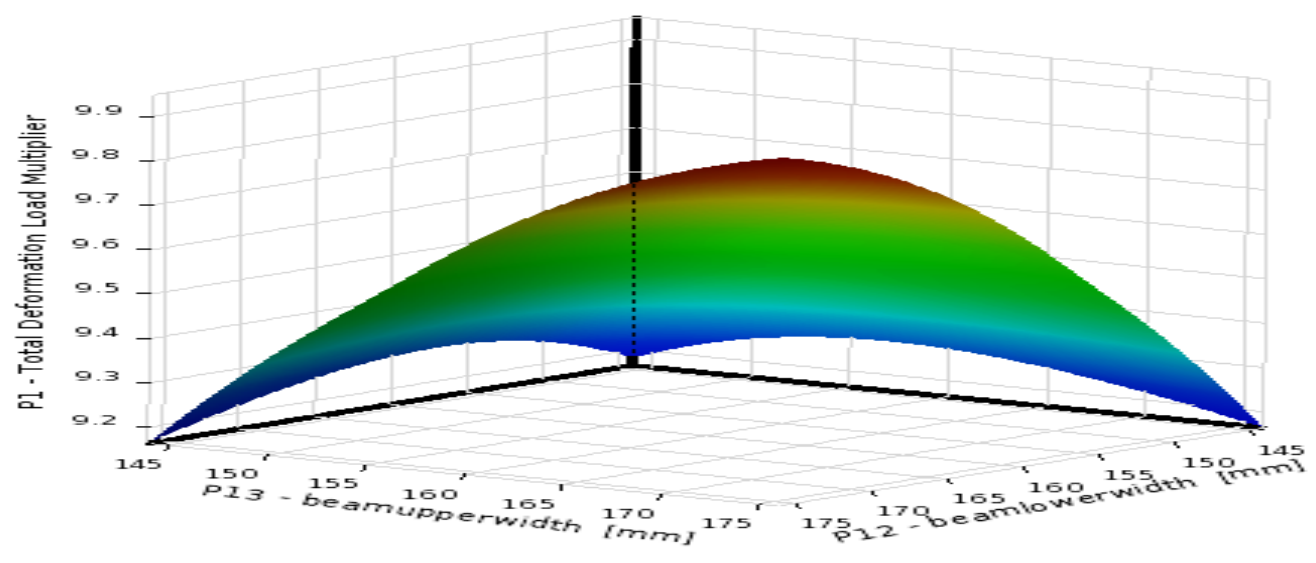

Figure 7 Response surface design

From the reaction surface plot as appeared in figure 8, the utmost high stress is acquired for width going $145 \mathrm{~mm}$ to $150 \mathrm{~mm}$ and for shaft upper width going from $145 \mathrm{~mm}$ to $150 \mathrm{~mm}$.

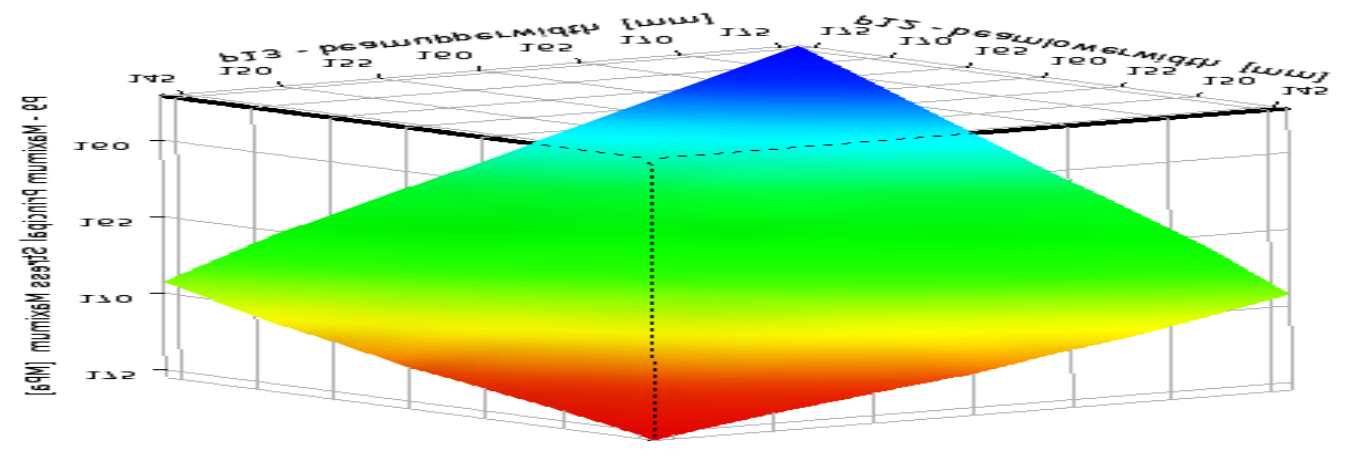

Figure 8 Response Surface - maximum principal stress

The least estimation of deformation is received for various scopes of shaft upper width as well as beam lower width appeared through dim blue forms for varying from $165 \mathrm{~mm}$ to $175 \mathrm{~mm}$. Elastic strain is greatest for shaft lower width measurement of $144 \mathrm{~mm}$ and diminishes directly up-to $176 \mathrm{~mm}$. From the reaction surface graph appeared in figure 9, the utmost deformation is acquired for lower width range $145-147 \mathrm{~mm}$ and $173 \mathrm{~mm}$ to $175 \mathrm{~mm}$ as well as for bar upper width under $145 \mathrm{~mm}$ to $147 \mathrm{~mm}$. 


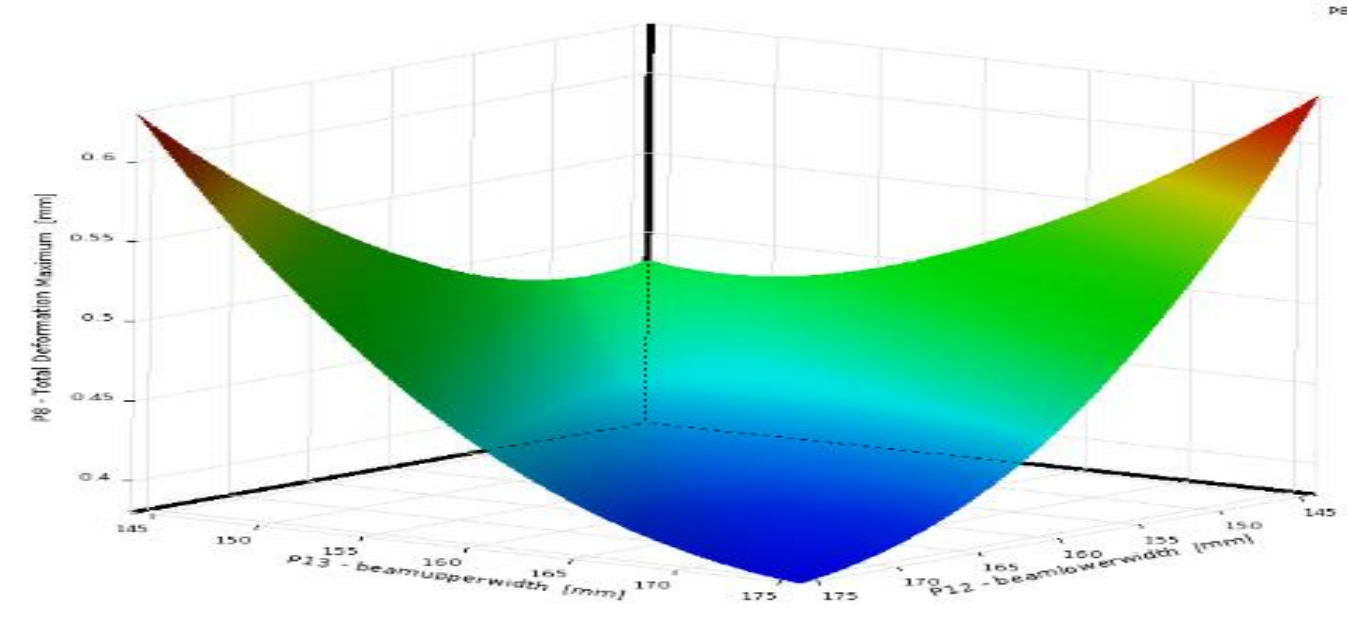

Figure 9 Response graph representation for overall deformation.

Elastic strain is most extreme for shaft upper width measurement of $144 \mathrm{~mm}$ and diminishes straight up-to $176 \mathrm{~mm}$. From the reaction surface plot as appeared in figure 10, the greatest strain is gotten for bar lower width going from $145 \mathrm{~mm}$ to $150 \mathrm{~mm}$ and for pillar upper width going from $145 \mathrm{~mm}$ to $150 \mathrm{~mm}$.

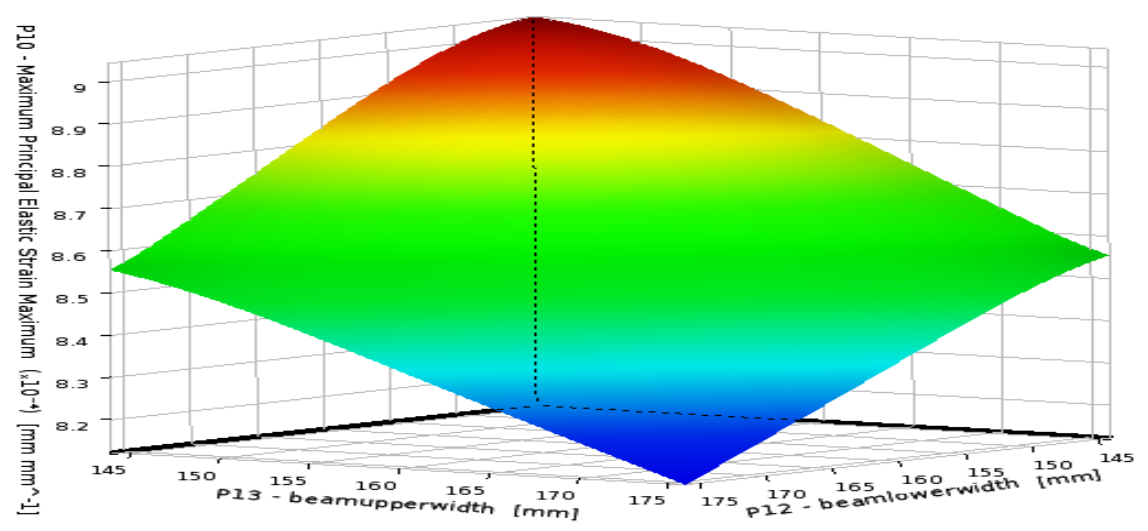

Figure 10 Response Surface plot- maximum principal-elastic strain

The plot represents enhance in secure parameters with enhance in beam lower width. The most reduced secure parameters are noticed for shaft lower width of $144 \mathrm{~mm}$ and greatest parameter is acquired for bar lower width of $176 \mathrm{~mm}$. There is an increment in safe factor with increment in beam upper width. The least parameter is noticed for shaft upper width of $144 \mathrm{~mm}$ as well as greatest wellbeing factor is acquired for bar upper width if $176 \mathrm{~mm}$. From the RS plot presented in figure 11, secure parameter minimum is highest for beam lower width from upto $175 \mathrm{~mm}$. 


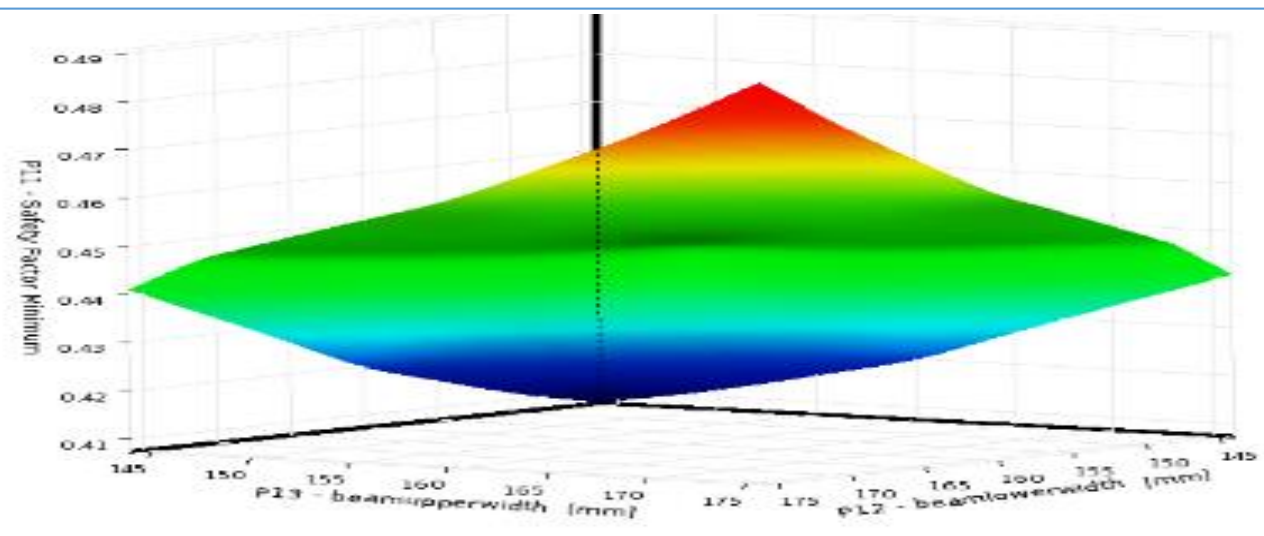

Figure 11 Response Surface plot - safety factor

The least estimation of secure parameter min is gotten for lower width from $145 \mathrm{~mm}$ to $150 \mathrm{~mm}$ as well as for upper width from $145 \mathrm{~mm}$ to $150 \mathrm{~mm}$. Safety factor variety regarding lower width represents increment in bowing second with increment in bar lower width. The most reduced SF is noticed for shaft lower width of $144 \mathrm{~mm}$ and greatest parameter is gotten for lower width of $176 \mathrm{~mm}$. Safety factor variety as for $\mathrm{r}$ upper width shows increment in bending moment with increment in upper width as shown in fig. 12 (a) and fig.12 (b) respectively.

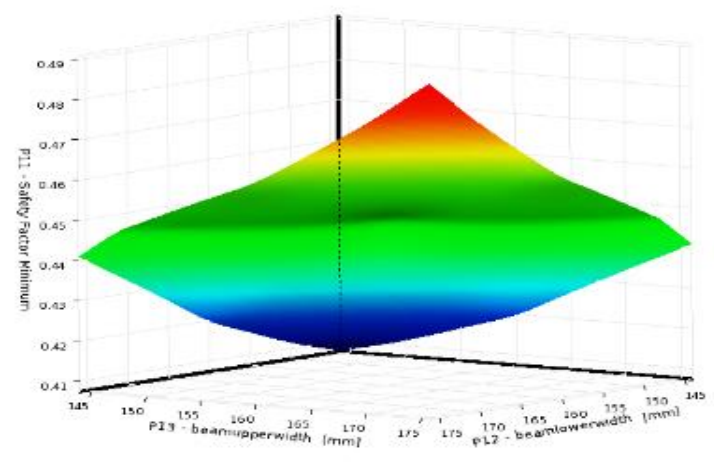

(a)

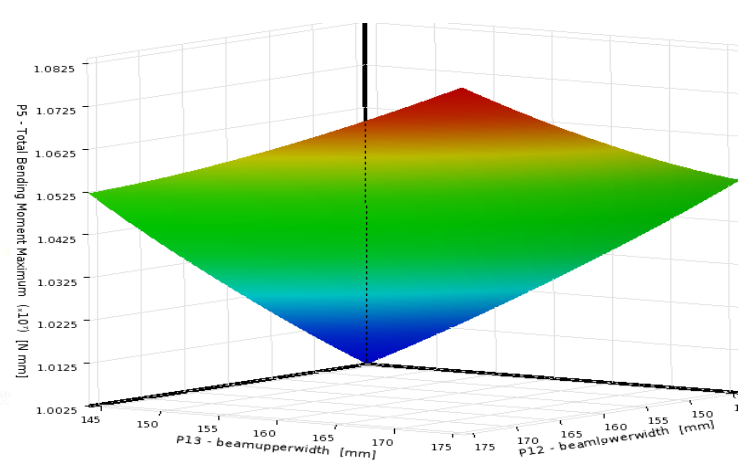

(b)

Figure 12 Response Surface plot safety factor (a) and total bending moment (b)

The least parameter is noticed for bar higher width of $144 \mathrm{~mm}$ and greatest SF parameter is acquired for upper width if $176 \mathrm{~mm}$. From the response surface plot, the bending moment is smallest is for beam lower width series from $145 \mathrm{~mm}$ to $150 \mathrm{~mm}$ and for beam upper width vary from $145 \mathrm{~mm}$ to $150 \mathrm{~mm}$. Bending moment maximum is for beam upper width varies from $170 \mathrm{~mm}$ to $175 \mathrm{~mm}$. The sensitivities-graph of various factors concentrated to decide its impact on yield factors in figure 13. This would empower researcher/designer to distinguish the enhancement variable, which might account extreme variety in yield variable. 


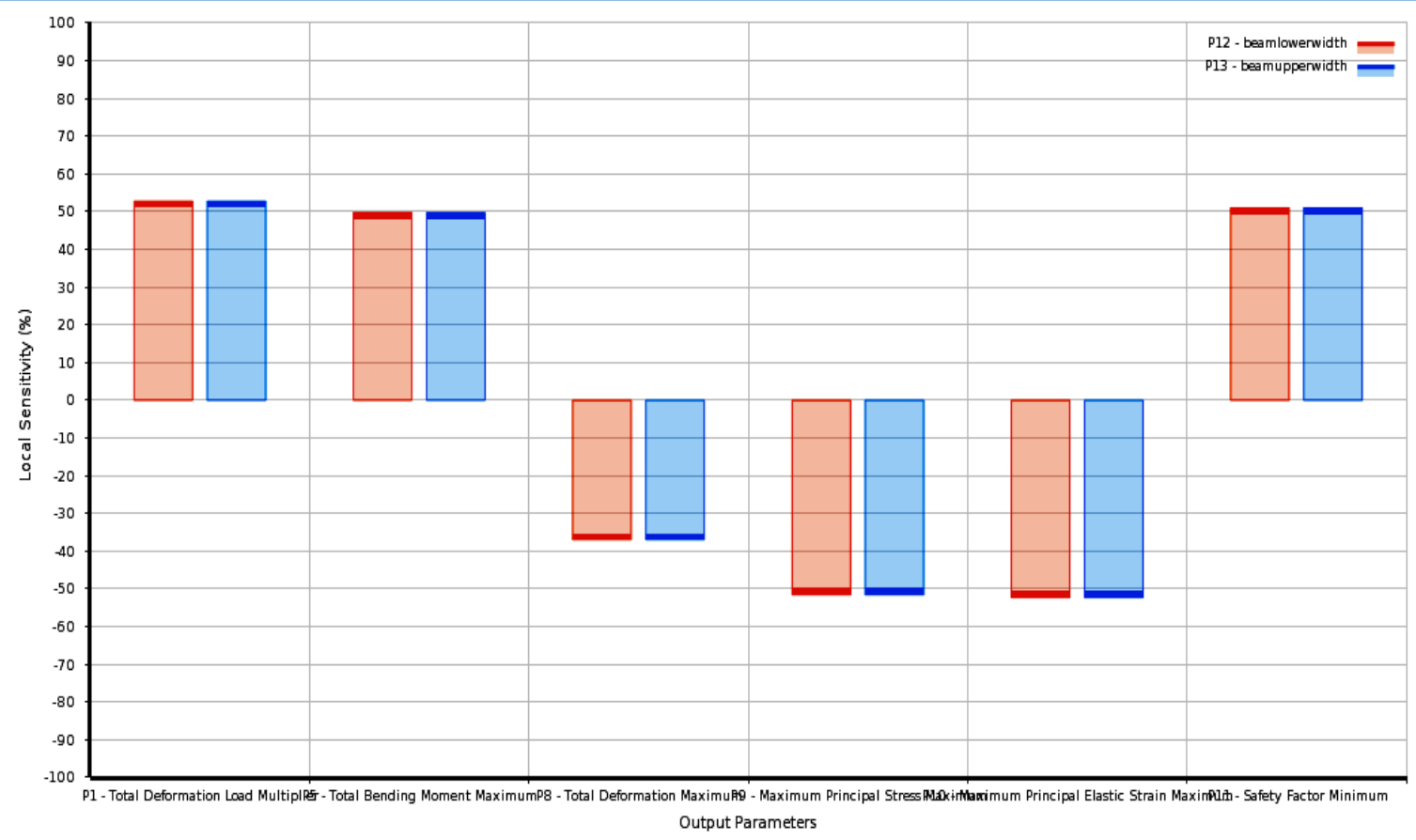

Figure 13 Sensitivity plot -several constraints indication

\section{CONCLUSION}

The static structural analysis conducted on stiffened rectangular plates with I shaped stiffeners. The findings of research are encouraging with respect to improved buckling resistance and increased overall stiffness of plate. The streamlined components of stiffeners got from Taguchi reaction surface technique likewise empowered to decide explicit arrangement of qualities for enhancement factors for example beam lower width as well as upper width. The reactions and sensitivities of enhancement factors are resolved, and discoveries are examined. For absolute bending moment multiplier variable both lower width and upper width shows positive value of sensitivities. The lower width affectability rate is $\mathbf{5 2 . 7 7}$ as well as upper width rate is also 52.77 (positive). In this way, Upper widths as well as lower width have same impact on complete deformation load multiplier. For maximum principal stress both beam lower width as well as beam upper width represents negative sensitivities of 51.539. The beam upper width size and beam lower dimension has similar influence on total deformation observed for SPSW. Beam lower size sensitivity rate is 52.295 as well as beam upper width sensitivity proportion is 52.295. Consequently, the upper width size as well as lower dimensions has similar outcome on maximum principal elastic strain noticed for SPSW. The lateral and longitudinal buckling characteristics of rectangular plates are significantly affected by type of opening and location of opening. A good scope of work lies in studying buckling behavior of rectangular plates with different types of openings, location of openings and material of plates. The application of 
MMC (Metal Matrix Composite) in rectangular plates along with different types of stiffeners can also be investigated

\section{REFERENCES}

Agarwal, A., O. M. Seretse, M. T. Letsatsi, and J. Pumwa. 2020. Optimization of Rectangular Plate with Circular Opening to Improve Buckling Characteristics. Pp. 97-105 in Advances in Lightweight Materials and Structures, Singapore: Springer Singapore.

Agarwal, A., O. M. Seretse, and J. Pumwa. 2020. Finite Element and Taguchi Response Analysis of the Application of Graphite Aluminum Mmc in Automotive Leaf Spring. Journal of mechanics of continua and mathematical sciences 15(7):168-79.

Emovon, Ikuobase, and Chinedum Ogonna Mgbemena. 2019. Enhancing the FMEA Technique Using a Combination of Expectation Interval, TAGUCHI, MOORA, and Geometric Mean Methods." Journal of Engineering Research (Kuwait) 7(4):238-60.

Grondin;, Mohammad R. Behbahanifard; Gilbert Y., and Alaa E. Elwi. 2003. Experimental and numerical investigation of steel plate shear wall. University ofAlberta, Edmonton, Alberta, Canada.

Letsatsi, M. T., and A. Agarwal. 2020. Optical Analysis of T-Shaped Stiffened Plate under Compressive Loading Using Central Composite Design Scheme. \{IOP\} Conference Series: Materials Science and Engineering 992:12001.

Letsatsi, M. T., O. M. Seretse, and A. Agarwal. 2020. Modelling and Structural Analysis of Stiffened Plate in Vertical Configuration Using ANSYS. Pp. 107-16 in Advances in Lightweight Materials and Structures,Singapore: Springer Singapore.

Li, Bin, Yanzhi Zhu, Fuzhou Qi, and Zhenxia Yuan. 2021. Failure of an Under-Dip Shale Slope and Its Response under Excavation Conditions. 9(March):63-72.

Louca, L. A., Y. G. Pan, and J. E. Harding. 1998. Response of Stiffened and Unstiffened Plates Subjected to Blast Loading. Engineering Structures 20(12):1079-86.

Pan, Youguang, and Luke A. Louca. 1999. Experimental and Numerical Studies on the Response of Stiffened Plates Subjected to Gas Explosions. Journal of Constructional Steel Research 52(2):171-93.

Rezai, Mahmoud. 1999. Seismic Behaviour of Steel Plate Shear Walls by Shake Table Testing. National Library of Canada = Bibliothèque nationale du Canada, 1999. 
Sharma, Neeraj, Wathiq Sleam Abduallah, Manish Garg, Rahul Dev Gupta, Rajesh Khanna, and Rakesh Chandmal Sharma. 2020. Optimization of TIG Welding Parameters for the 202 Stainless Steel Using NSGA-II. Journal of Engineering Research 8(4):206-21.

Takahashi, Y; Takemoto, Y; Takeda, T; Takagi, M. 1973. Experimental Study on Thin Steel Shear Walls and Particular Bracings Under Alternative Horizontal Load, Preliminary Report. Lisbon, Portugal.

Timler, P. A., and G. L. Kulak. 1983. Experimental Study of Steel Plate Shear Walls. Structural Engineering Report (114).

Vetr, Mohamad Ghasem, and F. Ghaffari. 2015. Effect of Vertical Flange Stiffener on Ductility of Slotted Web Exclusive Connection on (I)-Shape Profiles through Experimental Investigation. Journal of Engineering Research 3:1-15. 